\title{
ACTION OF A TROPHIC FACTOR(S) FROM RABBIT CORNEAL EPITHELIAL CULTURE ON DISSOCIATED TRIGEMINAL NEURONS ${ }^{1}$
}

\author{
K. Y. CHAN $^{*} \ddagger{ }^{2}$ AND R. H. HASCHKE $\$ \S$ \\ Departments of *Ophthalmology, $\ddagger$ Anesthesiology, and $\S B$ iochemistry (Adjunct), University of Washington, Seattle, Washington 98195
}

\begin{abstract}
Cultured corneal epithelial cells release a factor(s) that stimulates trigeminal neurons to form neurites in vitro. To characterize this trophic effect, conditioned media (serum free, supplemented) from cultures of corneal epithelium, stromal fibroblasts, and endothelium were studied further. Only epithelial conditioned medium (PCM) prolonged neuronal survival and induced neurite outgrowth. This trophic influence peaked after 2 to 3 days and gradually declined thereafter during a week when the medium was not renewed. Using a bioassay to score the percentage of initially viable neurons that extended neurites, it was found that the trophic effect of PCM was proportional to the conditioned medium concentration and to the cell density of the epithelial culture used for the conditioning. Maximum activity in PCM was correlated with confluency of the epithelial culture. Experiments using antiserum to nerve growth factor (NGF) and purified antibody to cold-insoluble globulin (CIG) indicated that the trophic effect of PCM was not derived from NGF or CIG. The trophic activity of PCM was abolished totally by heat or trypsin treatment but was not affected by collagenase. Although a fraction of the trophic activity was associated with the substratum after adsorption of PCM, this and other evidence did not suggest that the primary action of PCM was to enhance neuronal adhesion.
\end{abstract}

Trophic interactions between neurons and target cells have been studied extensively in vivo and in vitro for a better understanding of the basic mechanisms of neurogenesis (Varon and Bunge, 1978). The central hypothesis emphasizes the role of neuronotrophic factors produced by target cells in the survival, axon induction, differentiation, and maturation of neurons. Following purification, various neuronotrophic factors have been studied as extracts or as conditioned media (Varon and Bunge, 1978)

The cornea consists of three major cell types-epithelial cells, stromal fibroblasts, and endothelial cells-and receives sensory innervation from the trigeminal (Gasserian) ganglion. Sensory endings are confined to the epithelium (Hogan et al., 1971). Recent improvements in culturing pure rabbit corneal cells and dissociated neonatal trigeminal neurons have resulted in a co-culture system for studying trophic interactions between corneal cells and sensory neurons $(K$. Y. Chan and R. H.

\footnotetext{
' This work was supported by National Institutes of Health Research Grants EY-01756 and EY-01730 from the National Eye Institute, and some facilities were supported in part by National Institutes of Health Grant HD 02274. We wish to thank Dr. Ann Bunt for useful discussions and critical review of the manuscript and Ms. L. O'Gorman and N. Easterberg for technical assistance.

${ }^{2}$ To whom correspondence should be addressed at Department of Ophthalmology RJ-10, University of Washington, Seattle, WA 98195.
}

Haschke, submitted for publication). A cell-specific, contact-independent and a less specific contact-dependent trophic influence on neurons were demonstrated with these epithelial cells (K. Y. Chan and R. H. Haschke, submitted for publication). The specific influence appeared to be mediated by a diffusible factor(s). In this report, the putative neuronotrophic factor in conditioned medium from corneal epithelial culture was characterized further. Evidence was obtained that the epithelial cellderived material was not nerve growth factor (NGF), cold-insoluble globulin (fibronectin), or collagen.

\section{Materials and Methods}

Cell culture. Rabbit corneal epithelial cells, stromal fibroblasts, endothelial cells, and dissociated trigeminal neurons were isolated and cultured (K. Y. Chan and R. $H$. Haschke, submitted for publication). Cells were maintained in both serum-containing and serum-free supplemented culture medium. In the latter case, corneal cells were plated and cultured in serum-containing medium up to confluency ( 2 to 4 days for epithelial cells, 4 to 7 days for fibroblasts, and 7 to 11 days for endothelial cells), washed twice, and re-cultured in serum-free medium.

In addition to the primary cultures, fibroblasts and endothelial cells were also subcultured. For fibroblasts, cells were trypsinized in $0.25 \%$ trypsin (Difco Laboratories, Detroit, $\mathrm{MI}$ ) in $\mathrm{Ca}^{2+}-\mathrm{Mg}^{2+}$-free Puck's saline for 5 to 
$10 \mathrm{~min}$ at $37^{\circ} \mathrm{C}$, washed, and collected by centrifugation at $800 \times g$ for 5 min. For endothelial cells, the originally plated endothelium-Descemet's membrane pieces were dislodged from the culture dish by repeated flushing with medium which did not remove the attached monolayer cells, collected by pipetting, and re-seeded in a new dish.

Conditioned medium. Culture medium was collected from each corneal cell culture at 3- or 4-day intervals (1.5 to $2 \mathrm{ml} / 35-\mathrm{mm}$ dish). Cell debris was separated from the conditioned medium by centrifugation at $2,000 \times g$ for 15 min. With epithelial conditioned medium, the number of floating cells was estimated by resuspending the pellet after centrifugation and counting with a hemocytometer. Conditioned media were tested for neuronotrophic activity (see below) either fresh or after storage at $-20^{\circ} \mathrm{C}$ (stable up to 12 days for serum-containing medium and up to 7 days for serum-free medium).

Bioassay for neuronotrophic activity. Conditioned media from corneal cell cultures and other test substances were evaluated for their ability to prolong neuronal viability and induce neurite extension from rabbit trigeminal neurons (K. Y. Chan and R. H. Haschke, submitted for publication). The neurons were plated at a density of 3 to 4 cells $/ \mathrm{mm}^{2}$ and were free of non-neuronal cells of the ganglion. For the first 4 days after plating, the number of viable neurons with and without neurites longer than the neuron diameter were counted within two marked areas of $4 \times 10 \mathrm{~mm}$, each representing $20 \%$ of the surface area of the $16-\mathrm{mm}$ culture well. Each area for scoring contained 100 to 150 neurons and was scanned systematically without overlap using $\times 100$ magnification under an inverted microscope. Since observation by phase contrast microscopy was not satisfactory in the peripheral area of the culture well due to meniscus interference, scoring was made by bright-field observation. Criteria for distinguishing viable from non-viable neurons were established and correlated with trypan blue exclusion. In general, viable neurons $(28.7 \pm 0.4 \mu \mathrm{m}$ in diameter) appeared refractile, spherical, and smooth surfaced, whereas nonviable cells appeared pale, granular, and rough in profile. For the same area, the scoring value by bright-field examination matched that obtained after trypan blue staining and the variability of repeated scoring was less than $10 \%$. Neuronotrophic activity is defined as the highest percentage of initial viable neurons induced to extend neurites. The initial number of viable neurons was determined 1 day after plating and the maximum percentage of neurons extending neurites was obtained during the first 4 days of culture. About 30 to $40 \%$ of the plated neurons were viable after 1 day irrespective of the neuronotrophic activity of the test medium $(K . Y$. Chan and R. H. Haschke, submitted for publication). Conditioned medium was assayed without dilution except when the assay was saturated at about $90 \%$ neuronotrophic activity. Other test substances were dissolved in fresh culture medium for assay. NGF (2.5 S) and antiserum to $2.5 \mathrm{~S}$ NGF were obtained from Collaborative Research, Waltham, MA, purified cold-insoluble globulin (CIG) and purified antibody to CIG were gifts from Dr. Paul Bornstein (University of Washington) and rabbit serum was prepared by centrifugation of clotted blood at $35,000 \times g$ for $30 \mathrm{~min}$.

Coating experiments. To determine whether the neu- ronotrophic factor in epithelial conditioned medium would adsorb to the culture well, conditioned medium was preincubated for various periods at $4^{\circ} \mathrm{C}$ or room temperature, washed twice, and replaced with fresh medium (referred to as "coated" culture well). The "deprived" conditioned medium from the incubation then was transferred to a new culture well. Fresh medium containing 2.5 S NGF was subjected to the same treatment for comparison. Some coated culture wells (coated for $1 \mathrm{hr}$ at room temperature) were incubated further for $1 \mathrm{hr}$ at $37^{\circ} \mathrm{C}$ with $50 \mu \mathrm{g} / \mathrm{ml}$ of trypsin in $\mathrm{Ca}^{2+}-\mathrm{Mg}^{2+}$-free Puck's saline or purified collagenase (Form III, 2,800 units/ml; Advance Biofactures Co., Lynbrook, NY) in 25 $\mathrm{mm}$ Tris- $\mathrm{HCl}, \mathrm{pH} 7.4$, containing $10 \mathrm{~mm}$ calcium acetate. For testing the effect of NGF antiserum, culture wells were preincubated with $1 \mu \mathrm{g} / \mathrm{ml}$ of $\mathrm{NGF}$ or epithelial conditioned medium for $10 \mathrm{~min}$ at room temperature, washed twice, incubated with various concentrations of $\mathrm{NGF}$ antiserum in unconditioned medium for $10 \mathrm{~min}$, washed twice, and finally refilled with fresh unconditioned medium. The coated wells were assayed immediately for neuronotrophic activity.

Immunodiffusion test. Ouchterlony plates were prepared according to standard techniques (Ouchterlony and Nilsson, 1978) with $1 \%$ agar gel buffered at $\mathrm{pH} 8.6$ with $100 \mathrm{~mm}$ Tris-HCl. For sample application, $1 \mathrm{ml}$ of epithelial conditioned medium was concentrated with an Amicon dialysis cell using a YMIO membrane to a final volume of about $10 \mu \mathrm{l}$ (100-fold concentration). No loss of activity was detected in the conditioned medium after concentration. To a control sample of conditioned medium, purified NGF was added at $1 \mu \mathrm{g} / \mathrm{ml}$ before concentration. After $24 \mathrm{hr}$ at room temperature, the precipitin bands were photographed.

Morphometry of neurite length. The total length of neurites extended by randomly selected neurons on the first 3 days of culture was measured from phase contrast micrographs ( $\times 359$ magnification) using a map measure. Only those cells with non-overlapping neuritic fields were measured.

\section{Results}

Specificity and characteristics. Of the three corneal cell types, only epithelial conditioned medium induced neurite extension from trigeminal neurons (Fig. 1). Neurite initiation was observed as early as $5 \mathrm{hr}$ after plating. Neurons cultured in fresh medium or conditioned media from stromal fibroblasts and endothelial cells did not initiate neurites and their viability declined faster than those in epithelial conditioned medium. This specificity thus resembles the pattern of corneal innervation in vivo (Hogan et al., 1971). When epithelial conditioned medium was mixed with an equal volume of either fibroblast or endothelial conditioned medium, the percentage of neurons induced to extend neurites was the same as when the epithelial conditioned medium was diluted with fresh unconditioned medium, thus ruling out the presence of inhibitors in the other conditioned media. Similar to the results of non-contact co-culture with epithelial cells (K. Y. Chan and R. H. Haschke, submitted for publication), more neurons extended neurites after 2 days in epithelium-conditioned serum-free medium ( $72 \%$, Fig. $1 A)$ than in serum-containing medium $(51 \%)$. Subsequent experi- 

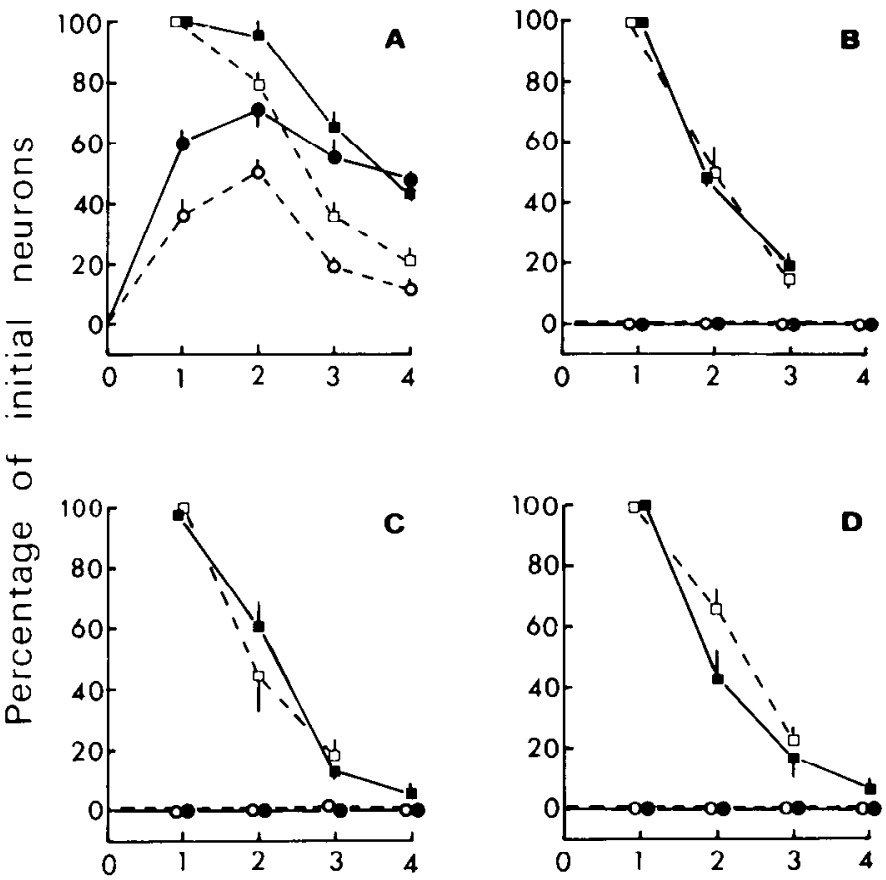

\section{Culture age (day)}

Figure 1. Effects of conditioned media from the three corneal cell types on dissociated trigeminal neurons. Conditioned media from 1- to 2-week cultures of rabbit corneal epithelial cells $(A)$, stromal fibroblasts $(B)$, endothelial cells $(C)$, and fresh unconditioned medium $(D)$ were used for maintaining dissociated neurons from neonatal trigeminal ganglia in culture. The percentages of initial neurons remaining viable $(\square$, in serum-free medium; $\square$, in serum-containing medium) and bearing neurites (O, in serum-free medium; $O$, in serum-containing medium) were determined on the first 4 days after plating. Corneal cell density per $35-\mathrm{mm}$ dish: epithelial, 1 to $1.5 \times 10^{5}$ cells; fibroblasts and endothelial, both 2 to $3 \times 10^{5}$ and 6 to $10 \times 10^{5}$ cells with no apparent differences in results. Each point is mean \pm SEM of three to seven experiments.

ments were performed using serum-free conditioned medium.

Several characteristics of neurite induction by epithelial conditioned medium were observed (Fig. 1). First, the percentage of neurons that was induced to form neurites approached a peak on the 2nd day (occasionally on the 3rd day) and declined thereafter. The slope of the decline was maintained through the 7 th day without medium change (data not shown). The same rate of decline was observed when the conditioned medium was diluted serially with various amounts of fresh medium or if the conditioned medium was collected in 2-day instead 3- or 4-day intervals. The decline was not attributed to neurite retraction but rather to gradual cell death, since dying neurons were seen microscopically with intact neurites that appeared shrunken, beaded, and granular (Fig. 2). Second, there was a close correlation between the percentage of neurons that extended neurites and subsequent neuronal survival. Usually by the 3 rd or 4 th day, only those neurons that extended neurites remained viable (Fig. 2).

Bioassays. In order to determine the quantitativeness of the bioassay, epithelial conditioned medium was di- luted serially with fresh medium and tested for neuronotrophic activity. As shown in Figure 3, the assay was linear over a wide range of concentrations that induced neurite extension of 5 to $75 \%$ of the neurons. In comparison, 0.02 to $1.0 \mu \mathrm{g} / \mathrm{ml}$ of $2.5 \mathrm{~S}$ NGF expressed neuronotrophic activity of only 30 to $50 \%$. By extrapolation, it would require over $100 \mu \mathrm{g} / \mathrm{ml}$ of NGF to produce $75 \%$ neuronotrophic activity. These dilution experiments also confirmed the positive correlation between the strength of conditioned medium and neuronal survival.

Morphometry was used to relate the total length of neurites to the neuronotrophic activity of conditioned medium. The actual length of neurites per neurite-bearing neuron increased continuously through the first 3 days despite the decline in the percentage of neurons extending neurites after the 2nd day (Table I). The greatest neurite lengths generally were found in cultures where the neuronotrophic activity was highest. Morphometry performed on neurons used in dilution and coating experiments (see below) also showed a correlation between neurite length and neuronotrophic activity. In comparison, although similar percentages of neurons extended neurites when co-cultured in contact with epithelial cells, stromal fibroblasts, or endothelial cells (K. Y. Chan and R. H. Haschke, submitted for publication), the length of neurites formed in the presence of epithelial cells was about 3 times greater than those formed in the presence of fibroblasts or endothelial cells (Table I).

Correlation with epithelial culture. Figure 4 shows a linear relationship between the number of attached epithelial cells in a culture and the neuronotrophic activity of conditioned medium collected from the culture. The histogram in Figure 5 shows that, during the 3-week culture, a proportion of the attached epithelial cells were gradually converted into floating cells and released into the culture medium. These floating cells were viable, non-mitotic, and structurally different from the attached cells (K. Y. Chan and R. H. Haschke, submitted for publication). This rate of release was independent of the initial cell density and changes observed in epithelial cell morphology. The neuronotrophic activity of conditioned medium collected from the same culture throughout this period also is shown in Figure 5. The activity appeared to build to a maximum in 7 to 11 days (during confluency) and declined rapidly thereafter. Media conditioned in the same manner by floating cells that were separated from attached cells 3 days after plating did not show any neuronotrophic effect. No inhibitory activity was detected in these negative or low activity conditioned media when they were mixed with equal volumes of conditioned medium collected during the confluent stage. The duration of maximum neuronotrophic activity was extended 3 to 5 days when the culture was maintained in serumcontaining medium or when the initial cell density was high (e.g., $1 \times 10^{6}$ cells).

Coating experiments. In order to determine whether the neuronotrophic factor could adsorb to the dish and still facilitate neurite extension, coating experiments were performed and the results are given in Table II. It appeared that the neuronotrophic factor adsorbed to the substratum at different temperatures and at an equilibration time of less than $1 \mathrm{~min}$. Except for a very weak batch of conditioned medium, not all of the original 

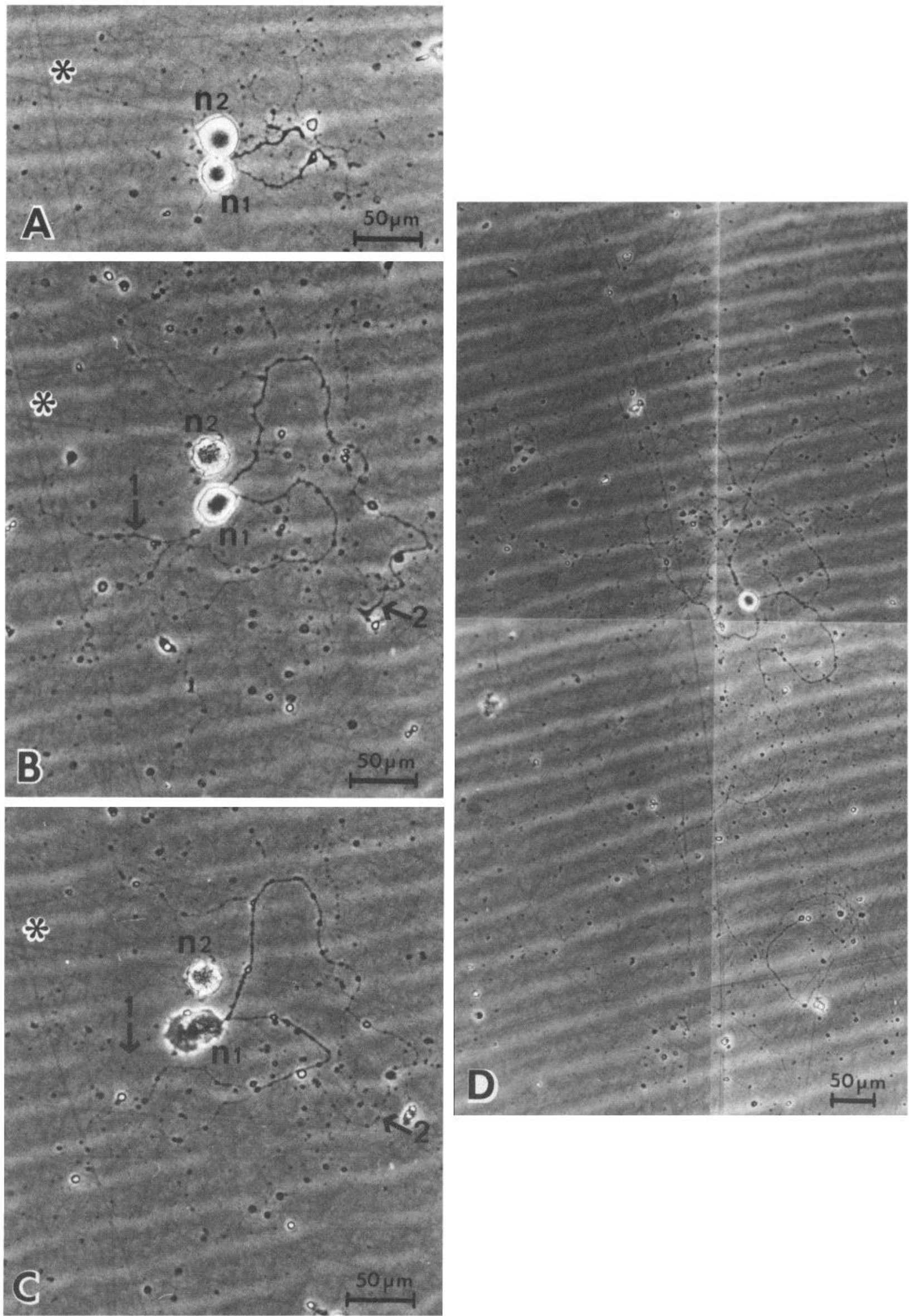


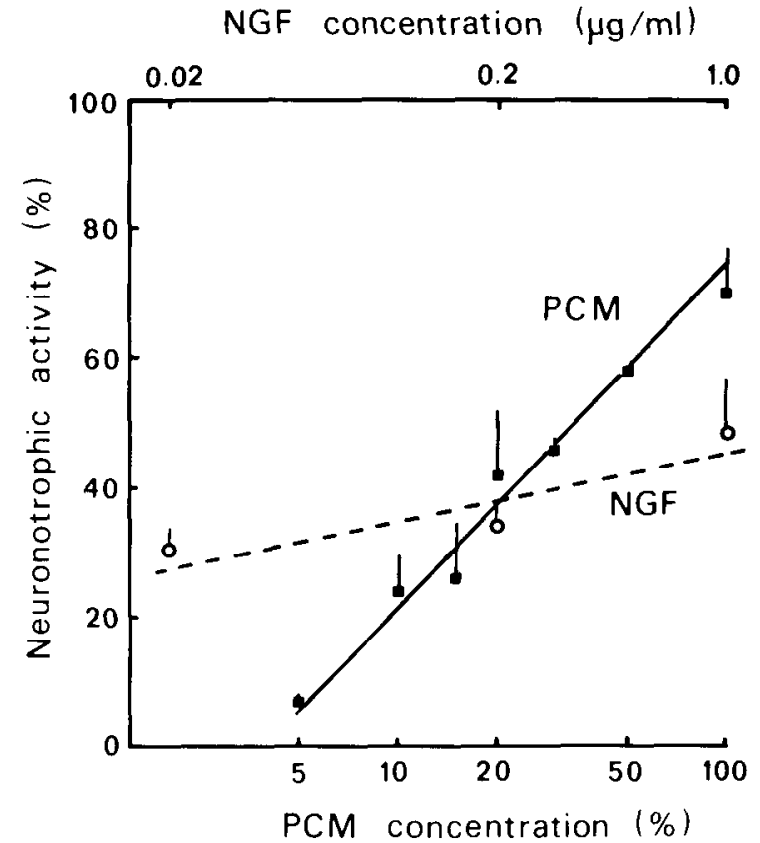

Figure 3. Concentration dependence of the trophic effect of epithelial conditioned medium (PCM) on dissociated neurons. Serum-free conditioned media were collected from 7-day epithelial cultures serially diluted with unconditioned medium (lower abscissa) and assayed for neuronotrophic activity (see "Materials and Methods"). Different concentrations of $2.5 \mathrm{~S}$ NGF (upper abscissa) were evaluated similarly. Each point is the average of duplicate experiments.

neuronotrophic activity was associated with the substratum after adsorption. A similar adsorption of NGF to the culture dish also was found (Table II). When the conditioned medium was totally depleted of neuronotrophic activity after coating or in control cultures using fresh unconditioned medium, the proportion of plated neurons that adhered to the culture well was the same as when the neuronotrophic factor or NGF was present. In all of the coating experiments, viability of neurons was correlated closely with the neuronotrophic activity expressed. The time course of neurite induction did not change when compared to the whole conditioned medium. When epithelial conditioned medium was diluted serially, adsorbed onto culture wells, and assayed in the presence of unconditioned medium, the expressed neuronotrophic activities were proportional to the dilution, similar to that shown in Figure 3.

Identification of neuronotrophic factor. Experiments were performed to determine whether the neuronotrophic factor in epithelial conditioned medium was similar to NGF or CIG. It was determined that a $0.5 \%$ solution of NGF antiserum totally abolished neurite formation that was induced by $1 \mu \mathrm{g} / \mathrm{ml}$ of NGF (neuronotrophic activity $=50 \%$ ) when both were added simultaneously in the assay. A 1 to $2 \%$ solution of the same antiserum inhibited by only $12 \%$ the neuronotrophic activity of epithelial conditioned medium (original activity $=90 \%$ ). A high antiserum concentration $(5 \%)$ inhibited the activity by $37 \%$, but much of this inhibition was a side effect of the added rabbit serum (also observed by Helfand et al., 1978) which appeared to interfere with the adhesion of neurons and neurites to the culture well. In order to avoid the nonspecific effect of serum in the bioassay, both NGF and epithelial conditioned medium were first adsorbed onto culture wells, exposed to various concentrations of NGF antiserum, and after thorough rinsing, tested for neuronotrophic activity in the presence of unconditioned medium (Table III). A 5\% antiserum solution that totally abolished the low neuronotrophic activity of adsorbed NGF did not affect the adsorbed neuronotrophic factor in conditioned medium of similar activity. In the Ouchterlony diffusion experiment, a precipitin band was observed as expected between the wells containing undiluted NGF antiserum and $1 \mu \mathrm{g}$ of NGF either alone or added to conditioned medium prior to concentration. However, no bands were present between the wells of NGF antiserum and a 100 -fold concentrated sample of epithelial conditioned media initially having a neuronotrophic activity of $85 \%$. Thus, no NGF immunoreactivity was demonstrated with the conditioned medium. Purified CIG either added directly or previously coated on culture wells at 10 or $30 \mu \mathrm{g} / \mathrm{ml}$ did not induce neurite extension in fresh medium. Conversely, purified antibody to CIG at 1 or $5 \mu \mathrm{g} / \mathrm{ml}$ did not affect the neuronotrophic activity of epithelial conditioned medium. Boiling for $3 \mathrm{~min}$ completely inactivated the conditioned medium. The neuronotrophic activity adsorbed onto the culture well was abolished totally by trypsin treatment but was not affected by collagenase.

\section{Discussion}

This report has presented evidence for the specific release of a neuronotrophic factor(s) from cultured corneal epithelial cells that acts on neonatal trigeminal neurons in culture. The term "epithelial neuronotrophic factor" (ENF) will be used to describe this factor or factors.

ENF was required for prolonged survival and neurite outgrowth of cultured trigeminal neurons. Under conditions in which ENF concentration and adsorption to substratum were varied, survival and neurite outgrowth of neurons were always correlated. In this regard, ENF was similar to NGF (Varon and Bunge, 1978). It is not known whether a single or multiple ENFs produced both effects. ENF-enhanced survival of neurons may have led to neurite induction or vice versa. In this study, neurite induction and not neuronal survival was chosen as the criterion for defining neuronotrophic activity because other conditioned media always failed to induce neurites, but some viable cells were present for 3 days as shown in Figure 1. From the time course study, it also appeared that using neurite induction as a criterion would provide a greater difference between the experimental and con-

Figure 2. Phase micrographs of trigeminal neurons cultured in serum-free epithelial conditioned medium. $A$, Two viable neurons; $n 1$ initiated neurites after 1 day. $B$, Same field after 3 days; neuron $n 1$ increased neurite outgrowth while neuron $n 2$ appeared shrunken. $C$, Same field after 4 days; neuron $n l$ died and some of its neurites disappeared (arrow 1) or appeared shrunken (arrow 2). Scratch lines on the plastic dish provided reference points for orientation (asterisk). $D$, A composite view of another field in the same culture after 4 days showing a surviving neuron with extensive neurite outgrowth. 
TABLE I

Correlation between the percentage of neurons bearing neurites and the total neurite length per neuron

The percentage of initially viable neurons that extended neurites as evaluated by bioassay (see "Materials and Methods") and the total length of neurites per neurite-bearing neuron as measured by morphometry (see "Materials and Methods") were obtained from neurons cultured in epithelial conditioned medium (PCM) and those co-cultured with cell contact with epithelial cells (EPC), stromal fibroblasts (SFC), or endothelial cells (ENC) in the absence of serum. (For co-culture experiments, see K. Y. Chan and R. H. Haschke, submitted for publication.) Each value for neurite length is the mean \pm SEM of the number of neurons indicated under $N$.

\begin{tabular}{|c|c|c|c|c|c|c|c|}
\hline \multirow{2}{*}{ Condition } & \multicolumn{3}{|c|}{ Percentage of Neurons Bearing Neurites } & \multicolumn{4}{|c|}{ Total Length of Neurites per Neuron } \\
\hline & Day 1 & Day 2 & Day 3 & $N$ & Day 1 & Day 2 & Day 3 \\
\hline & & & & & \multicolumn{3}{|c|}{$m m$} \\
\hline PCM & 70 & 94 & 87 & 7 & $4.0 \pm 0.7$ & $5.8 \pm 0.9$ & $8.2 \pm 1$ \\
\hline EPC & 34 & 53 & 59 & 7 & $2.6 \pm 0.3$ & $3.4 \pm 0.4$ & $4.0 \pm 0.6$ \\
\hline
\end{tabular}

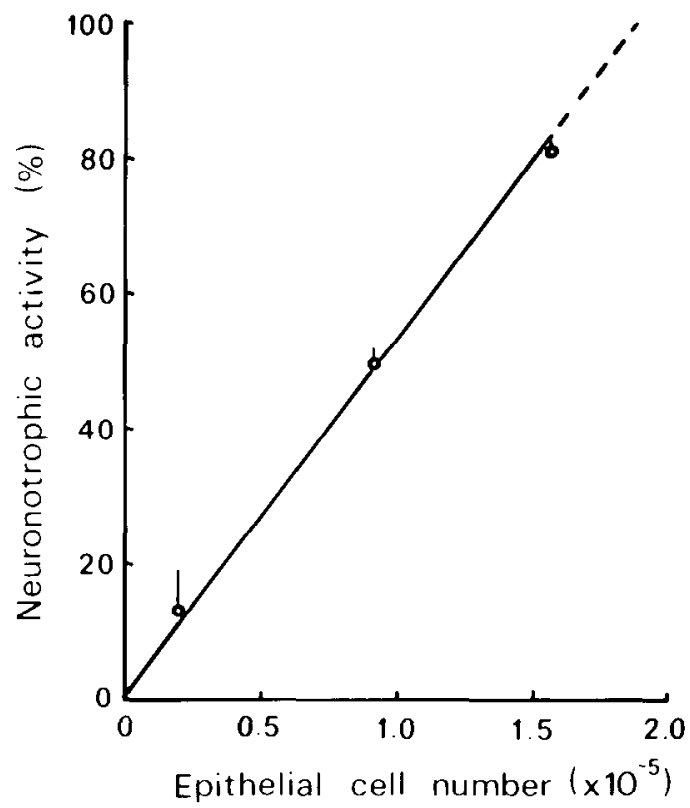

Figure 4. Dependence of neuronotrophic activity of epithelial conditioned medium on cell density of culture used for conditioning. Serum-free conditioned media were collected from 6 day epithelial cultures of different cell densities and assayed for neuronotrophic activity (see "Materials and Methods"). Each point is the average of duplicate determinations.

trol values at an earlier time (1st day). Thus, quantifying neurite induction was judged to be more sensitive, accurate, and convenient than evaluating neuronal survival in the bioassay.

The trophic effect of ENF on a population of neurons was slow acting and short lived. Neurite induction did not reach its maximum until the 2nd or 3rd day regardless of ENF concentrations and neuronal survival was prolonged by about 2 days. Compared to the extended survival rate of neurons co-cultured with epithelial cells (K. Y. Chan and R. H. Haschke, submitted for publication), it appeared that some additional factors were missing or diluted in the conditioned medium. It is possible that such missing factors might be involved in the contact-dependent type of trophic interaction. Alternatively, neurons might require a continuous supply (Varon and Bunge, 1978) of ENF which was not obtained without

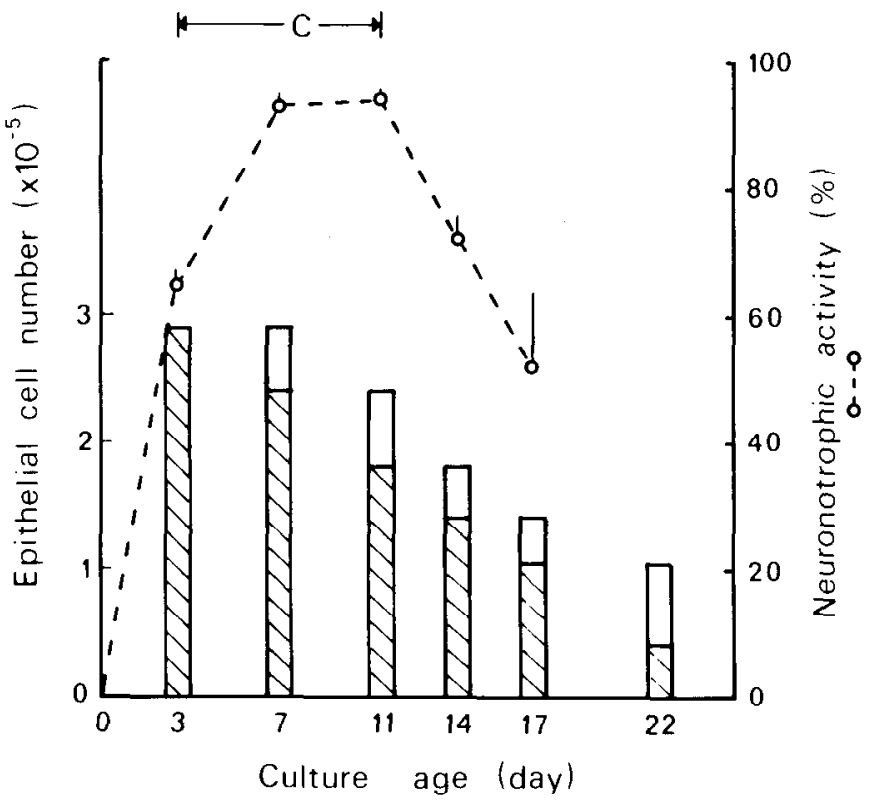

Figure 5. Correlation between neuronotrophic activity of epithelial conditioned medium and in vitro differentiation of the culture used for conditioning. About $7 \times 10^{5}$ epithelial cells were plated on a $35-\mathrm{mm}$ dish and the number of initially attached cells was estimated after 3 days by counting the number of floating cells in the collected medium. At subsequent changes of culture medium at 3- or 4-day intervals, the number of floating cells in the collected medium was counted and subtracted from the number of attached cells in the preceding period to estimate the number of attached cells currently remaining. After 22 days, the culture was trypsinized and the final number of attached cells was counted, verifying the accuracy of all previous estimations. The number of floating (open bars) and attached (hatched bars) cells estimated at each period is displayed as a histogram (left ordinate). The neuronotrophic activity of the collected media (right ordinate) also was assayed (see "Materials and Methods"). Each point is the average of duplicate determinations. $C$, confluency.

frequent renewal of medium. Relevant to this is the unknown fate of ENF; possibly it was internalized and affected intracellular functions before being degraded.

Neonatal trigeminal neurons appear somewhat heterogencous since, in the presence of ENF, some neurons did not form neurites, some initiated neurites but died 
TABLE II

Adsorption of neuronotrophic activity to plastic surface Epithelial conditioned media (PCM) of different neuronotrophic activities and $1 \mu \mathrm{g} / \mathrm{ml}$ of $2.5 \mathrm{~S} \mathrm{NGF}$ were added to plastic culture wells at a specified temperature and duration (coated well) and then transferred to another well (deprived medium). Coated wells were washed twice and refilled with fresh unconditioned medium. Dissociated neurons were added for the bioassay of neuronotrophic activity (see "Materials and Methods").

\begin{tabular}{|c|c|c|c|c|}
\hline \multirow[b]{2}{*}{$\begin{array}{l}\text { Trophic } \\
\text { Material }\end{array}$} & \multicolumn{4}{|c|}{ Neuronotrophic Activity } \\
\hline & $\begin{array}{l}\text { Original } \\
\text { Medium }\end{array}$ & Coated Well $(a)$ & $\begin{array}{l}\text { Deprived } \\
\text { Medium }(b)\end{array}$ & $\begin{array}{l}\text { Total } \\
\text { (Sum of } \\
a+b)\end{array}$ \\
\hline \multirow{5}{*}{ PCM } & & $\%$ & & \\
\hline & 38 & $\begin{array}{c}15 \\
\left(20^{\circ} \mathrm{C}, 1,5 \text {, or } 15 \mathrm{~min}\right)\end{array}$ & $-^{a}$ & - \\
\hline & 47 & $\begin{array}{c}20 \\
\left(20^{\circ} \mathrm{C}, 1 \mathrm{hr}\right)\end{array}$ & - & - \\
\hline & 17 & $\begin{array}{c}18 \\
\left(20^{\circ} \mathrm{C}, 1 \text { day }\right)\end{array}$ & 0 & 18 \\
\hline & 72 & $\begin{array}{c}21 \\
\left(4^{\circ} \mathrm{C}, 1 \text { day }\right)\end{array}$ & 27 & 48 \\
\hline \multirow[t]{2}{*}{$\mathrm{NGF}$} & 40 & $\begin{array}{c}9 \\
\left(20^{\circ} \mathrm{C}, 1 \mathrm{hr}\right)\end{array}$ & 24 & 33 \\
\hline & 48 & $\begin{array}{c}20 \\
\left(4^{\circ} \mathrm{C}, 1 \text { day }\right)\end{array}$ & 24 & 44 \\
\hline
\end{tabular}

${ }^{a}-$, not determined.

\section{TABLE III}

Effect of NGF antiserum on the neuronotrophic activity of epithelial conditioned medium

$\mathrm{NGF}$ and epithelial conditioned medium (PCM) were adsorbed onto culture wells and treated with rabbit antiserum to mouse $2.5 \mathrm{~S} \mathrm{NGF}$ before being assayed for neuronotrophic activity (see "Materials and Methods").

\begin{tabular}{cccc}
\hline \multirow{2}{*}{ NGF Antiserum Concentration } & \multicolumn{3}{c}{ Adsorbed Neuronotrophic Activity } \\
\cline { 3 - 3 } & NGF & PCM \\
\hline$\%$ & 21,31 & 24,40 \\
0 & 13,18 & $-{ }^{\circ}$ \\
0.1 & 6,9 & 35,39 \\
1 & - & 38,43 \\
2 & - & 47,53 \\
3 & 0,0 & 36,39 \\
5 & &
\end{tabular}

${ }^{a}-$, not determined.

after a few days, and some neurite-bearing neurons survived for a week with continuously increasing neurite length. Since the ophthalmic division of the trigeminal ganglion (where the neurons originated) consists only of sensory neurons, the heterogeneity may indicate that the cells were different with regard to their developmental state and/or their affinity and response to ENF. Thus, the selection process during neurogenesis whereby only a proportion of the initial neuronal population would develop a "long lasting" connection which is postulated to be mediated by neuronotrophic factors (Varon and Bunge, 1978) may have been observed in this study during the relatively short term in vitro assay.

Previous studies have shown for NGF that $(a)$ the induction of processes by PC12 cells saturated at $1 \mathrm{ng} /$ $\mathrm{ml}$ (Greene, 1977), (b) neurite outgrowth from cxplanted chick embryo sensory ganglia saturated at $1 \mu \mathrm{g} / \mathrm{ml}$ (Levi-
Montalcini and Angeletti, 1968; Varon et al., 1972), and (c) neuronal survival and growth of rat sympathetic neurons saturated at $0.5 \mu \mathrm{g} / \mathrm{ml}$ (Chun and Patterson, 1977). In this study, a concentration of $1 \mu \mathrm{g} / \mathrm{ml}$ of NGF induced neurite outgrowth from only $50 \%$ of the trigeminal neurons, whereas ENF could effect over $90 \%$ induction. Thus, it appeared that the conditioned medium was more effective in neurite induction than NGF. NGF antiserum at a concentration which totally abolished neurite outgrowth caused by $1 \mu \mathrm{g} / \mathrm{ml}$ of NGF did not affect the conditioned medium. The immunodiffusion results demonstrated that NGF immunoreactive substances were not present in conditioned medium at $1 \mu \mathrm{g} /$ $\mathrm{ml}$ or greater concentrations. Figure 3 shows that to obtain the degree of neurite formation observed, the conditioned medium would have to contain considerably greater than $1 \mu \mathrm{g} / \mathrm{ml}$ of $\mathrm{NGF}$. These results strongly suggested ENF and NGF were not the same substance. The protein nature of ENF was indicated by its sensitivity to heat and trypsin. Also, the ENF activity was retained without any significant loss following extensive dialysis or concentration by Amicon ultrafiltration.

Although the same percentage of neurons adhered to the culture dish in the presence or absence of ENF, this factor may still function in some manner to promote a "better" adhesion that results in neurite production. The lack of neurite induction with CIG and the lack of effect on ENF-induced neurite outgrowth with anti-CIG and collagenase also suggested that CIG or collagen would not account for the action of ENF. NGF also is capable of adsorbing to the culture dish (see also Pearce et al., 1973; Olender and Stach, 1977), but this property did not provide an adequate explanation for its trophic activities (see also Greene and Shooter, 1980).

The corneal epithelium in vivo consists of a single layer of mitotic basal cells, which migrate outward and differentiate into several layers of wing cells that further mature and give rise to the few layers of superficial cells at the exterior surface of the cornea (Hogan et al., 1971). Intraepithelial sensory terminals are confined mostly to the basal and wing cell layers and rarely extend into the superficial layers (Hogan et al., 1971). Therefore, the production of ENF by the epithelial culture, which increased up to confluency (Fig. 5), may indicate that ENF could have a biological function in directing sensory neurons during development. This hypothesis is being investigated further.

Among the numerous in vitro studies of trophic interactions between neurons and non-neuronal cells, many have demonstrated the presence of neuronotrophic factors in the target tissue of the neuronal system under study (Varon and Bunge, 1978; Brookes et al., 1980; Dribin and Barrett, 1980; Tuttle et al., 1980). For NGF, the most studied and well characterized trophic factor, its possible endogenous occurrence in target tissue was shown only recently (Ebendal et al., 1980). Another well studied factor is the cholinergic neuronotrophic factors (CNTF) from cultured heart tissue that act on dissociated ciliary neurons of chick embryo (Varon and Bunge, 1978). Since the parameters and bioassays used in studying CNTF in several laboratories were similar to those used for ENF in this study, it would be useful to compare the characteristics of these two factors. Except for pro- 
longing neuronal survival, inducing neurite outgrowth, and lack of identity to NGF, CNTF was different from ENF. CNTF was present only in conditioned medium initially containing 10\% serum (Varon et al., 1979; see also Collins, 1978a, b; Nishi and Berg, 1979; exception: Helfand et al., 1978). Two separate components were identified: a non-adsorptive component that only enhanced neuronal survival and an adsorptive component that only induced neurite outgrowth (Collins, 1978b; Adler and Varon, 1980). The biological activity of the neurite-promoting component was expressed only on polycation- or collagen-coated substratum (Varon et al., 1979; Nishi and Berg, 1979) and not on plastic (Collins, 1978b). Thus, the primary action of this component appeared to be to enhance neuron adhesion. This component was also fast acting: the peak effect was observed after 1.5 to $4 \mathrm{hr}$ (Collins, 1978a). Therefore, based on these comparisons, ENF possesses some characteristics similar to NGF and CNTF, but otherwise appears to be distinctly different from them.

This study has employed culture techniques such as defined medium without serum, uncoated plastic substratum, and pure cultures of both target cells and neurons without contamination by a third cell type so that unambiguous interpretation of the data was possible. The last feature is especially crucial since it has been shown that fibroblasts and neuronal satellite cells can produce various trophic factors including NGF (Oger et al., 1974; Young et al., 1975; Banker, 1980). Further studies of the in vivo occurrences, biochemical properties, physiological functions, and mode of action of ENF will be necessary for our understanding of the cornea-trigeminal interrelationship in various normal, diseased, and healing states.

\section{References}

Adler, R., and S. Varon (1980) Cholinergic neuronotrophic factor: V. Segregation of survival and neurite-promoting activities in heart-conditioned media. Brain Res. 188: 437-448.

Banker, G. A. (1980) Trophic interactions between astroglial cells and hippocampal neurons in culture. Science 209: 809810 .

Brookes, N., D. R. Burt, A. M. Goldberg, and G. G. Bierkamper (1980) The influence of muscle-conditioned medium on cholinergic maturation in spinal cord cell cultures. Brain Res. 186: 474-479.

Chun, L. L. Y., and P. H. Patterson (1977) Role of nerve growth factor in the development of rat sympathetic neurons in vitro. I. Survival, growth, and differentiation of catecholamine production. J. Cell Biol. 75: 694-704.

Collins, F. (1978a) Axon initiation by ciliary neurons in culture. Dev. Biol. 65: 50-57.

Collins, F. (1978b) Induction of neurite outgrowth by a condi- tioned-medium factor bound to the culture substratum. Proc. Natl. Acad. Sci. U. S. A. 75: 5210-5213.

Dribin, L. B., and J. N. Barrett (1980) Conditioned medium enhances neuritic outgrowth from rat spinal cord explants. Dev. Biol. 74: 184-195.

Ebendal, T., L. Olson, A. Seiger, and K. -O. Hedlund (1980) Nerve growth factors in the rat iris. Nature 286: 25-28.

Greene, L. A. (1977) A quantitative bioassay for nerve growth factor (NGF) activity employing a clonal pheochromocytoma cell line. Brain Res. 133: 350-353.

Greene, L. A., and E. M. Shooter (1980) The nerve growth factor: Biochemistry, synthesis, and mechanism of action. Annu. Rev. Neurosci. 3: 353-402.

Helfand, S. L., R. J. Riopelle, and N. K. Wessells (1978) Nonequivalence of conditioned medium and nerve growth factor for sympathetic, parasympathetic, and sensory neurons. Exp. Cell Res. 11.3: 39-45

Hogan, M. J., J. A. Alvarado, and J. E. Weddell (1971) Histology of the Human Eye, pp. 55-111, W. B. Saunders, Philadelphia.

Levi-Montalcini, R., and P. U. Angeletti (1968) The nerve growth factor. Physiol. Rev. 48: 534-569.

Nishi, R., and D. K. Berg (1979) Survival and development of ciliary ganglion neurons grown alone in cell culture. Nature 277: 232-234.

Oger, J., B. G. W. Arnason, N. Pantazis, J. Lehrich, and M. Young (1974) Synthesis of nerve growth factor by $L$ and 3T3 cells in culture. Proc. Natl. Acad. Sci. U. S. A. 71: 1554-1558.

Olender, E. J., and R. W. Stach (1977) High affinity, specific binding of $\left[{ }^{125} \mathrm{I}\right] \beta$ nerve growth factor to glass beads. Biochem. Biophys. Res. Commun. 79: 561-568.

Ouchterlony, O., and L. -A. Nilsson (1978) Immunodiffusion and immunoelectrophoresis. In Handbook of Experimental Immunology. Vol. 1: Immunochemistry, D. M. Weir, ed., pp. 19.1-19.44, Blackwell Scientific Publications, Oxford, England.

Pearce, F. L., D. V. Banthorpe, J. M. Cook, and C. A. Vernon (1973) Adsorption of nerve growth factor onto surfaces: Implications for the assay in tissue culture. Eur. J. Biochem. 32: 569-575.

Tuttle, J. B., J. B. Suszkiw, and M. Ard (1980) Long-term survival and development of dissociated parasympathetic neurons in culture. Brain Res. 183: 161-180.

Varon, S. S., and R. P. Bunge (1978) Trophic mechanisms in the peripheral nervous system. Annu. Rev. Neurosci. 1: 327361.

Varon, S., J. Nomura, J. R. Perez-Polo, and E. M. Shooter (1972) The isolation and assay of the nerve growth factor proteins. In Methods and Techniques of Neurosciences, $\mathrm{R}$. Fried, ed., pp. 203-229, Marcel Dekker, New York.

Varon, S., M. Manthorpe, and R. Adler (1979) Cholinergic neuronotrophic factors: I. Survival, neurite outgrowth and choline acetyltransferase activity in monolayer cultures from chick embryo ciliary ganglia. Brain Res. 173: 29-45.

Young, M., J. Oger, M. H. Blanchard, H. Asdourian, H. Amos, and B. G. W. Arnson (1975) Secretion of a nerve growth factor by primary chick fibroblast cultures. Science 187: 361362. 